\title{
Necessidades de informação e competências informacionais no setor público: um estudo de caso*
}

Silvânia Vieira de Miranda

\section{Introdução}

Este documento resume parte do referencial teórico de uma pesquisa de doutorado e alguns resultados do estudo de caso realizado. O objetivo da pesquisa foi estudar as necessidades de informação (NI) e as competências informacionais (CI) dos supervisores indiretos de instituições financeiras no Brasil. A premissa inicial foi que a atividade de Supervisão Indireta de Instituições Financeiras (SIIF) era intensiva em informação e poderia ser estudada a partir de parâmetros ligados ao trabalho informacional. Os parâmetros escolhidos foram o ciclo e os contextos de comunicação da informação, e a tecnologia da informação ${ }^{1}$.

O conteúdo do texto está composto do referencial teórico referente às NI e às CI, do referencial metodológico e das técnicas de pesquisa utilizadas, dos resultados e análise das informações geradas, das conclusões e, finalmente, das notas e referências presentes no texto. 


\section{Referencial teórico}

O tema necessidades de informação faz parte da área de pesquisa denominada Estudos de Usuários em Ciência da Informação, na qual foram acumuladas várias pesquisas, contando com diferentes linhas teóricas onde podem ser agrupados diversos autores de renome. Não se pretendeu neste texto abordar em profundidade e extensão esse referencial teórico, dado o limite de espaço do documento. A abordagem das competências ainda está em fase de consolidação nos contextos acadêmico e organizacional, estando centrada em temas de grande complexidade, como o conhecimento humano e a aprendizagem. Não se pretendeu discutir aqui todos os conceitos envolvidos nem as origens históricas e as correntes teóricas da abordagem, e sim apresentar conceitos básicos que fornecessem uma base mínima para a discussão dos resultados da pesquisa realizada. Não foram localizadas pesquisas científicas que tratassem das necessidades de informação e/ou das competências dos profissionais da atividade de SIIF. Os resultados $\mathrm{da}$ presente pesquisa constituem-se, portanto, em um marco inicial para a construção de conhecimento nos dois temas de estudo no referido contexto.

\section{Necessidades de informação}

Para o presente texto, foram selecionados apenas os autores escolhidos como referência para os modelos teóricoconceituais elaborados para a pesquisa. Estudos de NI interessam-se pela forma com que uma pessoa analisa necessidades, entra em contato com um sistema de informação e constrói sentido para suas atividades. A NI traduz o estado em que um usuário se encontra quando se confronta com a exigência de uma informação que lhe falta (e é necessária) para prosseguir seu trabalho. Ela nasce tanto de um impulso de ordem cognitiva, dentro de um dado contexto (problema a resolver, objetivo a atingir), quanto da constatação da insuficiência ou inadequação de conhecimentos que solucionem problemas ou cumpram objetivos, levando o usuário a buscar informações com o objetivo de modificar seu estado. A quantidade de informação que um usuário absorve não é em função do número de páginas lidas, mas de processos mentais de integração dos novos dados e informações a uma estrutura pessoal de conhecimento (LE COADIC, 1998; Wilson, 2000).

As necessidades nascem, também, dos papéis dos indivíduos na vida social, sendo que o mais relevante deles é o papel exercido no trabalho, representando um conjunto de atividades, responsabilidades do indivíduo na busca de seu sustento e/ ou outros propósitos. Obter resultados em uma tarefa particular, planejar e tomar decisão são atividades geradoras de necessidades cognitivas. A natureza do ambiente combinada com a estrutura da personalidade individual cria as necessidades afetivas. Os ambientes sociais e organizacionais afetam a motivação individual, os usos da informação e seus fluxos, tornando importante o entendimento de como o modelo da organização afeta o comportamento individual de busca de informação, ou seja, a estrutura, a tecnologia, as tarefas e as pessoas. São questões centrais nos estudos de NI: por que o usuário decide buscar informação; qual propósito ele acredita servir; e que uso é feito com a informação recebida. As estruturas mentais preexistentes, nas quais uma informação toma forma, estão ligadas ao mundo social e organizacional em que se insere o usuário 
e que fornecem condições para a construção de significados (LE COADIC, 1998; WiLson, 1981, 2000 e 2002).

Processos de busca e uso da informação são construídos cognitiva e emocionalmente e, também, de forma situacional e dinâmica. $\mathrm{O}$ uso da informação depende de como o indivíduo avalia a relevância cognitiva e emocional da informação recebida. E também está condicionado a atributos objetivos capazes de determinar a pertinência da informação a uma determinada situação problemática. As NI estão determinadas: 1) pela percepção de lacunas no conhecimento e na capacidade de dar sentido a problemas ou tarefas; 2) por fatores emocionais inerentes à incerteza, nível de stress, e dificuldade existente ao perceber essas lacunas; e 3) por fatores situacionais encontrados em contextos e experiências específicos (como clareza e consenso quanto aos objetivos, restrição de recursos, magnitude de riscos, formas de controle, normas profissionais e sociais, tempo etc.) (Choo, 1999 e 2003).

Uma representação do modelo teórico-conceitual de análise das NI pode ser visto na Figura 2. O desenvolvimento das NI é considerado em três dimensões, estando também representados os fatores que interferem no processo de percepção dessas NI (fatores intervenientes, mecanismos de ativação). $\mathrm{O}$ construto reúne elementos dos modelos desenvolvidos por Choo (2006) e Wilson (2000a).

\section{Competência informacional}

A abordagem da competência, no nível individual, provém da busca de alternativas para programas de educação e gestão das relações de trabalho nas novas condições socioeconômicas da Sociedade da Informação. Duas correntes tratam do assunto: 1) a gestão de RH, que preconiza o uso da competência para integrar a gestão de pessoas a partir do conceito de competência nos seus processos; 2) a sociologia da educação e do trabalho, que trata dos aspectos psicossociais da utilização da competência em programas educacionais e níveis de qualificação da mão-de-obra e de emprego (Guimarães, 2000). A corrente de gestão de RH faz parte de uma primeira

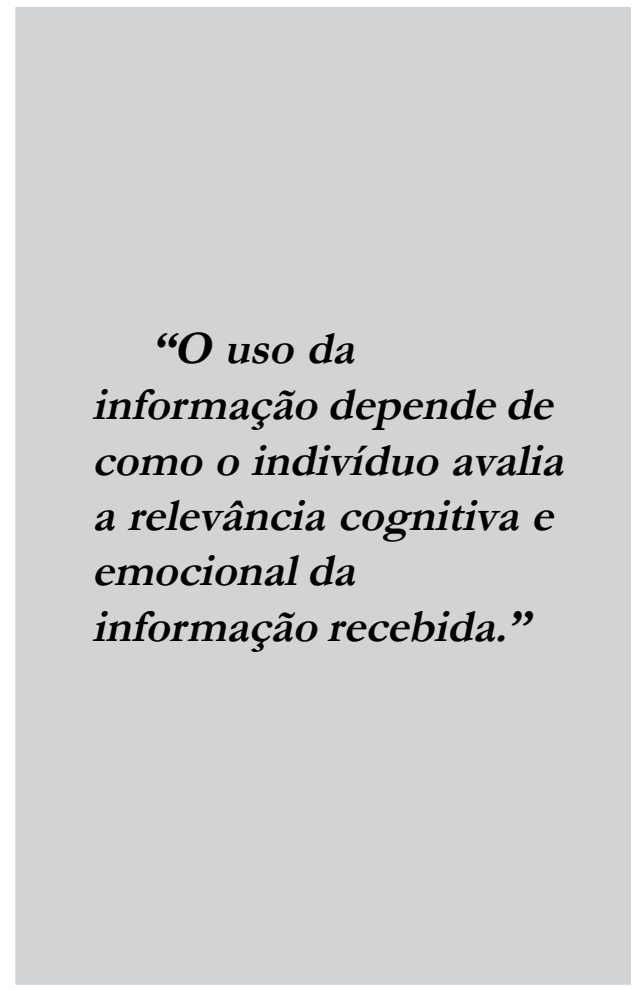

geração que tomou o ser humano como "recurso" a ser permanentemente desenvolvido e atualizado.

A corrente da sociologia da educação e do trabalho usa a "lógica da competência". Isso significa uma mudança radical em relação ao modelo do posto de trabalho vigente na sociedade industrial. A competência refere-se a recursos possuídos e/ou adquiridos e colocados em ação em uma 
situação prática. Seria a iniciativa, sob a condição de autonomia, pressupondo a mobilização dos recursos internos pessoais (adquiridos e desenvolvidos pelos indivíduos em dada situação) e dos coletivos (trazidos e colocados à disposição pelas organizações). Saber mobilizar e combinar recursos, ter capacidade de integrar saberes diversos e heterogêneos para realizar atividades é demonstrar competência. A lógica de integração do saber, do saber fazer, dos comportamentos se estabelece em função das exigências da situação de trabalho. A competência profissional reside na própria mobilização dos recursos e não neles mesmos. A passagem do saber à ação é uma reconstrução: um processo de agregação de valor (ZARIFIAN, 2001 e 2003; Le Boterf, 2003).

No nível organizacional, a abordagem teve como objetivo melhorias de desempenho organizacional por meio do desenvolvimento de competências que conferissem diferenciação e competitividade às empresas. As competências organizacionais são constituídas a partir da combinação de recursos e de múltiplas competências individuais, de tal forma que o resultado total é maior do que a soma das competências individuais. Ao definir sua estratégia competitiva, a empresa identifica as competências essenciais do negócio e as competências necessárias a cada função. As competências essenciais são desenvolvidas em processos de aprender-ao-fazer, em contextos específicos à empresa ou de colaboração entre empresas. São características da competência essencial: ser específica, única, difícil de imitar, e trazer grande contribuição ao valor percebido pelo cliente. Devido a essas qualidades distintivas elas podem proporcionar vantagens competitivas à organização (Fleury e Fleury, 2001; Grant, 1996; Prahalad e Hamel, 1990).
A Competência Informacional (CI) é um conjunto de competências colocado em ação ao trabalhar com a informação, podendo ser expressa pela expertise em lidar com o ciclo e as tecnologias da informação e com os contextos informacionais. Essa competência, mobilizada em situações de trabalho, pode ser vista como um dos requisitos do perfil profissional necessário ao trabalho informacional presente em qualquer atividade, pois perpassa processos de negócio, gerenciais e técnicos diversos, e diferentes partes de uma mesma organização ou atividade. Ela pode ser comparada a competências de fundo, que são adquiridas em situação educativa e formalizadas em conquistas cognitivas e comportamentais necessárias para enfrentar as categorias de situações-problema onde o trabalho com a informação tem papel primordial, mesmo que não apareça no resultado final da atividade. (Miranda, 2004, 2007).

As competências informacionais têm sido abordadas no tema Information Literacy, que trata da educação para a informação. Esse tema de estudo tem gerado diversas pesquisas, mas ainda não há clareza conceitual sobre o termo literacy, que envolve sérias questões de polissemia. $\mathrm{Na}$ Europa utiliza-se mais freqüentemente o conceito ligado à educação e à alfabetização. No Brasil aparece ainda o conceito de letramento, ou seja, o tema está ligado à pessoa, enquanto letrada, educada, alfabetizada em informação, dentro da Sociedade da Informação (VIRKus, 2003; Marcial, 2003; Dudziak, 2001). Pesquisas em Information Literacy tratam das competências informacionais como parte importante de suas preocupações. No entanto, a educação para informação é um tema maior, que se relaciona ao papel educativo que podem exercer os profissionais de 
informação ${ }^{2}$, dado que suas competências específicas são basicamente informacionais.

Uma representação do modelo de análise das CI está na Figura 2. O construto foi elaborado a partir dos referenciais teóricos de Zarifian (2004) e Le Boterf (2003), considerando as três dimensões de desenvolvimento das competências.

A ligação entre as necessidades de informação e as competências informacionais

No plano das definições teóricas, as NI e as CI partilham dimensões constitutivas: tanto as NI quanto as competências podem ser entendidas em três dimensões: cognitivas, emocionais e situacionais. $\mathrm{O}$ saber acumulado está ligado às condições cognitivas, considerando que a estrutura prévia de conhecimentos dos indivíduos é primordial para a evolução do saber. A ligação entre o saber fazer e as condições situacionais existe na medida em que as situações de trabalho estabelecem as condições de desenvolvimento da busca e o uso da informação e sua influência na construção de competências (habilidades). O saber agir e as condições emocionais estão ligados porque o ambiente engendra os elementos que influenciam o modo de agir dos profissionais em questão e a formação de suas competências (atitudes "memória emocional" conectada à escolha dos caminhos tomados). A correspondência sugerida entre as dimensões das NI e das CI está representada na Figura 1.

Considera-se que as soluções visualizadas para atender uma NI provavelmente correspondem a CIs desenvolvidas para lidar com os problemas já solucionados, com as anomalias/insuficiências de conhecimento diante de situações já vivenciadas, e/ou com os vazios de sentido diante de modificações ocorridas no ambiente, conforme está representado na Figura 2.

\section{Referencial metodológico e técnicas usadas}

A base ontológico-epistemológica considerada compatível com os construtos teóricos formulados para a pesquisa envolvia uma elaboração teórica constante, ao longo de todo o processo de pesquisa. Dadas a lacuna teórica no tema estudado e a complexidade do ambiente de pesquisa,

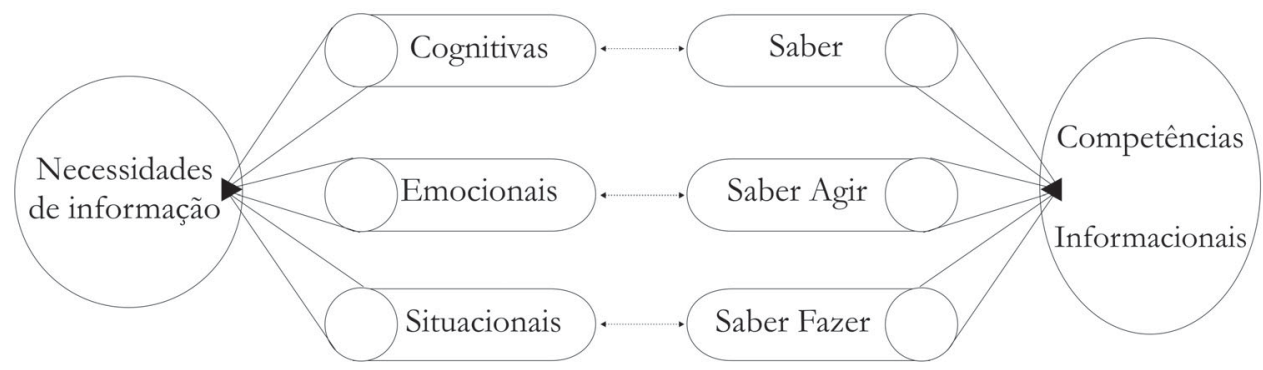

Fonte: Miranda, 2007

Figura 1: Relacionamento entre as dimensões das NI e das competências. 


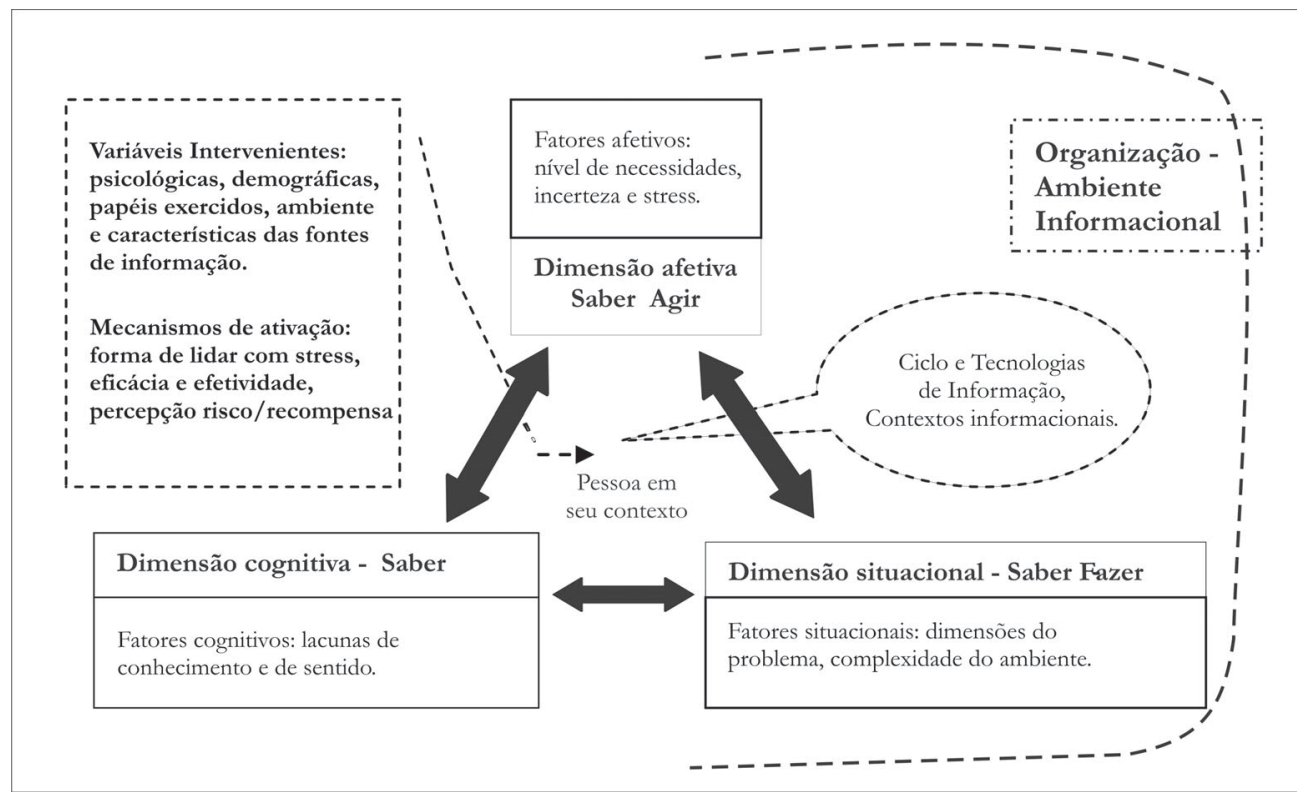

Fonte: Miranda, 2007

\section{Figura 2: As dimensões e elementos das NI e das CI.}

a abordagem metodológica deveria proporcionar um relacionamento entre os momentos teórico e prático da pesquisa de maneira a obter uma compreensão paulatina sobre como poderiam surgir e serem identificadas as NI e como poderiam ser desenvolvidas as competências relacionadas a elas.

González Rey (2005) propôs uma abordagem subjetivo-interpretativa, cujas unidades constitutivas essenciais são os "sentidos subjetivos" que expressam a diversidade de aspectos objetivos da vida social. A isso o autor associou uma epistemologia qualitativa que se apóia em um conjunto de princípios gerais de construção do conhecimento, dos quais podem ser ressaltados: o caráter construtivo-interpretativo e interativo do conhecimento e o papel do singular. O objetivo central de uma pesquisa seria, para o autor, construir "modelos teóricos compreensivos" e com valor explicativo sobre sistemas complexos. Considerados à maneira de González Rey, os construtos teóricos formulados para o presente estudo forneceriam um guia para a coleta de dados e interpretação das informações geradas. Durante todo o processo de pesquisa seriam geradas informações e formuladas idéias constantemente durante a fase empírica da pesquisa, até que se pudesse obter um construto final que oferecesse um entendimento mais completo no confronto com a realidade.

Foi realizado um estudo de caso cujo objetivo era estudar as NI e as competências da atividade de SIIF no Brasil. Essa atividade é exercida em diferentes países por instituições reguladoras, normalmente governamentais, sendo que cada país adota um determinado formato de funcionamento, dependendo do desenvolvimento histórico do sistema financeiro e da própria 
atividade no país. No Brasil, cuida-se do acompanhamento global e consolidado do sistema financeiro, por meio do monitoramento de risco das IF. O objeto de estudo da pesquisa foi a atividade de SIIF no Brasil, sendo seus profissionais os sujeitos da pesquisa. A população considerada era composta do grupo decisório da atividade organizacional - oito pessoas mais 47 profissionais ligados especificamente às tarefas da supervisão indireta.

A coleta de dados foi realizada de acordo com procedimentos específicos referentes aos temas envolvidos: o mapeamento de NI seguiu as proposições de Le Coadic (1998); e o mapeamento das CI seguiu os procedimentos de Zarifian (2003). O formato metodológico usado foi uma composição de técnicas que possibilitou aprofundamento paulatino da compreensão sobre a visão de mundo deste grupo de usuários de informação e suas competências em quatro fases sucessivas, culminando em uma construção teórica final:

1) na primeira fase da pesquisa foi usada a técnica da pesquisa documental com o objetivo de definir a atividade a ser estudada; caracterizar a instituição responsável pela atividade e a unidade organizacional que executava as tarefas; e definir a população e os sujeitos de pesquisa;

2) na segunda fase foi usada a técnica da entrevista. Foram consultadas as pessoas em cargo de decisão, cuja percepção permitiria obter informações sobre a organização, a estratégia e os fatores essenciais que influíam no seu funcionamento, para identificar os Fatores Críticos de Sucesso $(\mathrm{FCS})^{3}$ da atividade de SIIF;

3) na terceira fase foi usada a técnica da observação participante para mapear os processos; as tarefas; os problemas e situações-problema; os documentos e informações mais utilizados; os produtos e serviços de informação existentes; as TI utilizadas no ambiente; os fatores que impulsionavam as pessoas a buscar informação; os conhecimentos, as habilidades e atitudes dos profissionais em suas tarefas diárias. A influência da estrutura organizacional e da hierarquia funcional também foi observada no trabalho diário dos profissionais;

4) na última fase, para avaliação das informações obtidas com as técnicas

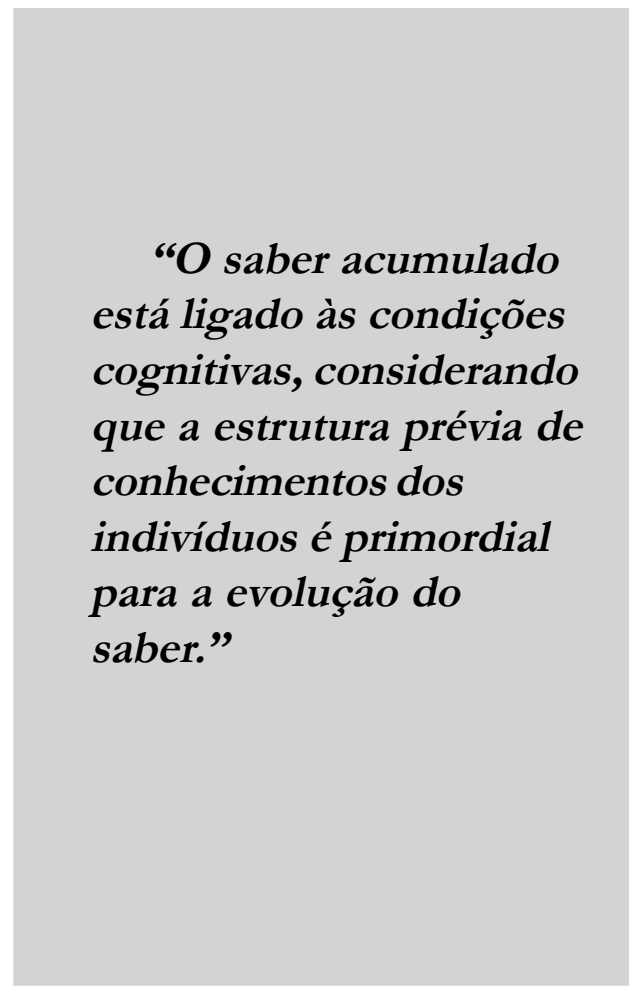

precedentes e triangulação final dos dados, foi usada a técnica da discussão em grupo (grupo focal). Isso possibilitou cotejar todos os dados e as informações geradas e confirmar as análises da pesquisadora vis-a-vis ao ponto de vista dos próprios profissionais.

As técnicas de registro da coleta de dados foram o caderno de notas e o 
gravador. Os instrumentos de coleta de dados foram roteiros de questões preparados em cada fase da pesquisa, além do completamento de frases. A técnica escolhida para analisar as entrevistas e as anotações de campo foi a análise de conteúdo, na forma da análise categoria temática, conforme Franco (2005) e Valentim (2004). Com relação ao instrumento de completamento de frases foi utilizada a técnica de análise de discurso, seguindo a sugestão de Almeida (2005).

Procurou-se com o estudo compreender a SIIF como atividade informacional, cujas necessidades específicas requeriam o desenvolvimento de competências apropriadas no tocante ao trabalho com a informação. O mapeamento das NI e das competências ligadas à informação levou em conta suas dimensões constitutivas, identificando-as nas fases do ciclo da informação, e no uso das TI e dos contextos informacionais.

\section{Resultados, análise e discussão das informações geradas}

As NI foram relacionadas a um conjunto de fontes e canais de informação mais utilizados, ciclos e fluxos detectados no ambiente, gerando informações para o entendimento das dimensões cognitivas, sociais e situacionais envolvidas na busca e no uso da informação no ambiente pesquisado. Foram estabelecidos os perfis da atividade e dos profissionais estudados. Obteve-se uma lista de competências conhecimentos, habilidades e atitudes detectadas nas situações práticas diárias do trabalho com a informação, de forma a suprir as NI existentes.

A atividade se relaciona à coleta, tratamento e divulgação de informações agregadas sobre o sistema financeiro brasileiro. A estratégia utilizada é monitorar os vários tipos de risco por meio de processos de trabalho específicos com grupos de profissionais específicos, da forma mais automatizada possível. Cada tipo de risco é detalhado e especificado para diminuir a complexidade dos problemas e aumentar a segurança e extensão do processo de monitoramento. Utiliza-se a TI em larga escala, possibilitando aos analistas se preocupar somente com análise dos sinais de problemas de acordo com os tipos de risco verificados por uma ferramenta de trabalho. A automatização de processos transferiu informações e conhecimentos básicos da "tecnologia de supervisão" para uma ferramenta de trabalho, desonerando o supervisor das fases de coleta, seleção, tratamento e armazenamento das informações e conhecimentos básicos de cada processo. Somente fatores situacionais específicos que influem em determinados problemas detectados são examinados, o que reduz a quantidade de tarefas e a quantidade de informações utilizadas.

Os produtos principais da atividade são relatórios de análise das informações coletadas e comunicados e/ou informação direta aos decisores. A maioria dos produtos e serviços é de consumo e de divulgação internos à organização. Os clientes da supervisão indireta são a supervisão direta, que pode se valer de relatórios com análises prévias antes de se dirigir a uma instituição para fiscalizá-la; a diretoria, que se apóia em informações consolidadas e tempestivas para tomar decisões; outras unidades organizacionais interessadas nos serviços informacionais disponíveis; e o público externo interessado em informações agregadas sobre o sistema financeiro. As ferramentas de trabalho utilizadas na atividade são sistemas de informação 
desenhados para responder aos formatos de coleta e de análise de dados necessários ao supervisor indireto, bem como a metodologias, critérios e indicadores construídos especificamente para o monitoramento que realizam. Os FCS identificados da atividade estudada estão relacionados na Tabela 1. indireta depende da capacidade de sinergia, cooperação e comunicação constante com outras áreas da organização e seus fornecedores de informação. As NI estão ligadas, principalmente, aos fatores situacionais que a atividade inflige. Os recursos informacionais provenientes de fontes externas carecem de verificação

\section{Tabela 1: Os fatores críticos de sucesso da SIIF}

\begin{tabular}{|l|}
\hline Capacidade de Agregação, Integração e Comparação. \\
\hline $\begin{array}{l}\text { Capacidade de Monitoramento Permanente e Concomitante do Sistema Financeiro como } \\
\text { um todo. }\end{array}$ \\
\hline Capacidade de Otimização e Racionalização. \\
\hline Possuir Sinergia e Capacidade de Comunicação com outras áreas da organização. \\
\hline Possuir Base Legal e Regulamentar para a ação. \\
\hline Possuir Capacidade de Retenção de Pessoal. \\
\hline \\
\hline Possuir/Fornecer Informação com Qualidade e Tempestividade. \\
\hline Ter fontes de informação autônomas, integradas, acessíveis / disponíveis por níveis de sigilo. \\
\hline Possuir uma Base Tecnológica adequada. \\
\hline Possuir Produtos e Serviços que tenham Visibilidade. \\
\hline \\
\hline Possuir Qualificação, Perfil e Treinamento adequados. \\
\hline Possuir Motivação. \\
\hline Capacidade de Criar e Inovar. \\
\hline Capacidade de Comunicação e Cooperação. \\
\hline
\end{tabular}

Fonte: Miranda (2007)

Os recursos críticos apontados como necessários para que a atividade cumpra seus objetivos envolvem a capacidade de gerar informações agregadas, integradas e comparativas e realizar o monitoramento constante e concomitante das IF. Isso é alcançado otimizando recursos tecnológicos e de pessoal e racionalizando processos de trabalho, dada a escassez desses dois tipos de recursos, principalmente dos adequados para a atividade. O bom funcionamento da supervisão quanto à veracidade e confiabilidade. É essencial uma base tecnológica adequada para trabalhar com grandes volumes de informação, diversificada tanto em formatos e tecnologias quanto em conteúdos. As NI dos supervisores indiretos estão ligadas à posse de uma base tecnológica que possibilite trabalhar com a informação necessária, no formato e qualidade necessários. Sem a TI adequada seria inviável realizar a supervisão indireta de maneira satisfatória. Dado o perfil da 
atividade e o uso intenso da informação e da TI, o perfil profissional tem uma especificidade expressa por algumas qualidades consideradas críticas: inovação, criatividade, comunicação, cooperação, motivação. As NI são marcadas pela diversidade das informações necessárias para realizar as tarefas e pelo uso dos sistemas de informação em cada processo de trabalho.

A elaboração de ferramentas de trabalho objetiva incluir as "regras de negócio" em programas de computador e automatizar tarefas. A automatização do ciclo da informação oferece rapidez, maior segurança e desonera o supervisor indireto dos processos informacionais mecânicos, concentrando-o na análise do risco propriamente dito, e direcionando-o para a pesquisa minuciosa dos problemas detectados. O conhecimento sobre as ferramentas, as metodologias, indicadores e critérios incluídos nas ferramentas continua necessário ao analista, pois conhecer os instrumentos de trabalho, suas possibilidades e limites também faz parte do perfil. Os processos de trabalho foram analisados com relação ao ciclo e à tecnologia da informação e aos contextos informacionais. Sua representação esquemática está na Figura 3.

As NI para a SIIF estão estreitamente ligadas aos seus processos de trabalho, principalmente ao nível de uso da TI nesses processos. Quanto menos automatizado o processo, maior a quantidade e diversidade de informações necessárias para analisar os riscos. O uso da TI e a automatização dos

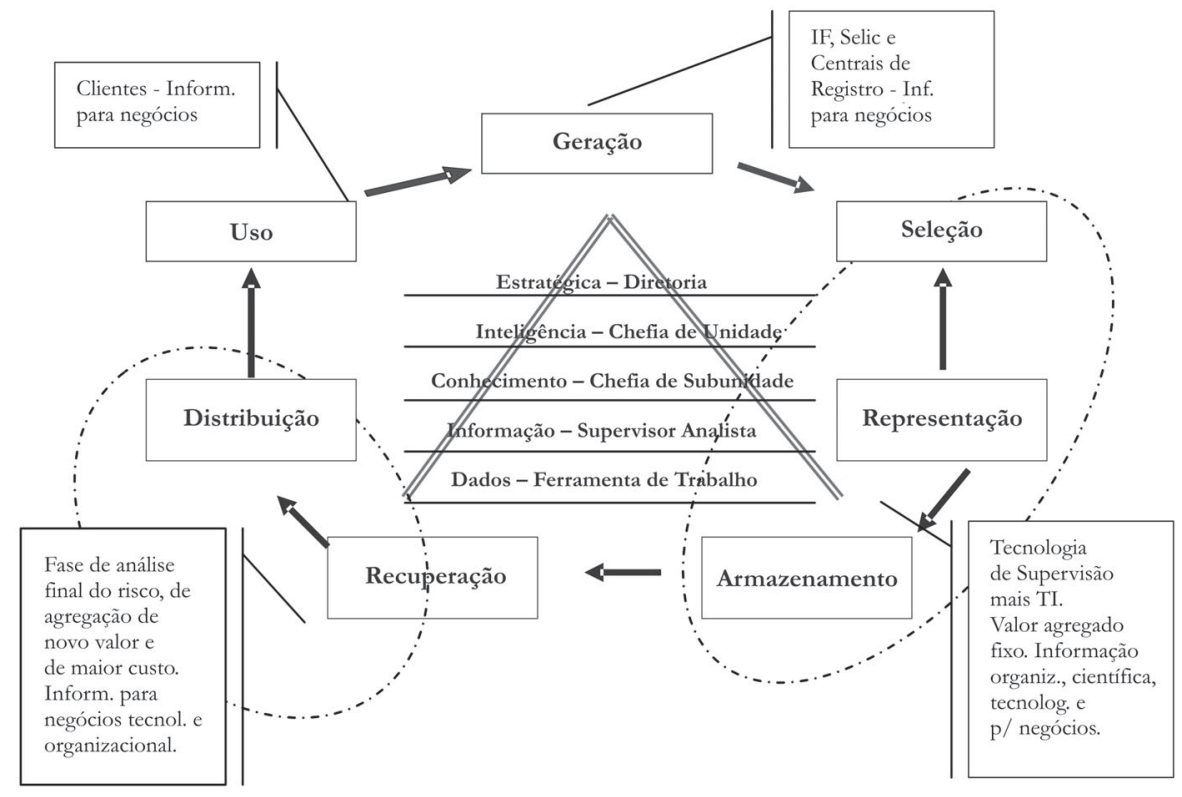

Fonte: Miranda, 2007

Figura 3: Ciclo, contextos e Tecnologia da Informação nos processos de trabalho da SIIF no Brasil. 
processos facilitaram, melhoraram o desempenho e a segurança das análises, reduzindo a quantidade de informações necessárias. No entanto, isso tornou a análise final mais profunda e minuciosa, envolvendo um perfil profissional mais específico para realizá-la.

\section{As competências informacionais} nos processos de trabalho.

A Tabela 2 apresenta as competências por processo de trabalho, descritas como comportamentos esperados na prática do trabalho. verificam a consistência entre a contabilidade das IF e as outras fontes de dados, e a situação de cada IF com relação ao risco. Os outros dois processos de trabalho (4 e 5) fazem o monitoramento constante das operações de todas as IF, traçando cenários e curvas de stress. Os processsos utilizam informações das IF e de fontes alternativas, buscando verificar a consistência das informações fornecidas ao órgão supervisor. Esse desenho permite traçar cenários específicos de comportamento baseando-se em parâmetros de mercado.

Tabela 2-As competências que podem atender às NI dos supervisores indiretos

\begin{tabular}{|c|l|l}
\hline $\begin{array}{c}\text { Processo de } \\
\text { Trabalho }\end{array}$ & $\begin{array}{l}\text { Problemas que ocasionavam NI } \\
\text { em cada processo de trabalho }\end{array}$ & $\begin{array}{l}\text { Descrição da competência } \\
\text { que poderia atender essas NI }\end{array}$ \\
\hline $\begin{array}{c}\text { Processo de } \\
\text { trabalho 1 }\end{array}$ & $\begin{array}{l}\text { Qual a significância e relevância de uma } \\
\text { dada variação patrimonial (identificada } \\
\text { pela ferramenta de trabalho) para o } \\
\text { funcionamento normal de uma dada IF? }\end{array}$ & $\begin{array}{l}\text { Faz análise da situação econômico- } \\
\text { financeira da IF para detectar variações } \\
\text { significativas e relevantes na evolução } \\
\text { dos seus ativos e passivos. }\end{array}$ \\
\hline $\begin{array}{c}\text { Processo de } \\
\text { trabalho 2 }\end{array}$ & $\begin{array}{l}\text { Qual a coerência existente entre a } \\
\text { contabilidade de uma IF e os registros } \\
\text { de suas operações no mercado? }\end{array}$ & $\begin{array}{l}\text { Faz análise da consistência entre os } \\
\text { ativos e passivos das IF e o registro } \\
\text { de suas operações no mercado. }\end{array}$ \\
\hline $\begin{array}{c}\text { Processo de } \\
\text { trabalho 3 }\end{array}$ & $\begin{array}{l}\text { Qual o risco associado a uma variação } \\
\text { dos ativos líquidos e/ou à necessidade } \\
\text { estimada de liquidez de uma IF (apontada } \\
\text { pela ferramenta de trabalho), por si } \\
\text { mesma e enquanto tendência futura? }\end{array}$ & $\begin{array}{l}\text { Faz avaliação da situação de liquidez } \\
\text { de uma IF para apontar irregularidades } \\
\text { e tendências futuras. }\end{array}$ \\
\hline $\begin{array}{c}\text { Processo de } \\
\text { trabalho 4 }\end{array}$ & $\begin{array}{l}\text { Por que uma dada operação realizada por } \\
\text { uma IF (identificada pela ferramenta de } \\
\text { trabalho) não foi efetivada obedecendo } \\
\text { aos parâmetros de negociação do mercado? }\end{array}$ & $\begin{array}{l}\text { Faz análise das operações atípicas do } \\
\text { mercado de Títulos Públicos Federais } \\
\text { para apontar irregularidades e } \\
\text { tendências futuras. }\end{array}$ \\
\hline $\begin{array}{c}\text { Processo de } \\
\text { trabalho 5 }\end{array}$ & $\begin{array}{l}\text { Qual a situação de uma dada IF com } \\
\text { relação ao risco no seu mercado? }\end{array}$ & $\begin{array}{l}\text { Atribui notas quantitativas que } \\
\text { classificam uma IF com relação aos } \\
\text { riscos em seu mercado. }\end{array}$ \\
\hline
\end{tabular}

Fonte: Miranda, 2007.

A análise das variações significativas e relevantes dos ativos e passivos das IF (processo 1) integra informações contábeis e econômico-financeiras para monitorar sistemática e continuamente o comportamento patrimonial das IF. Essa análise é complementada pelos processos 2 e 3 , que
A competência essencial da atividade foi descrita como a capacidade de usar informações agregadas e integradas para realizar monitoramento constante e concomitante do sistema financeiro. Integrar grande quantidade e diversidade de informações e monitorar constantemente o sistema 
financeiro como um todo constantemente é o que diferencia a atividade de supervisão indireta da supervisão direta, que é uma atividade similar e complementar e que monitora as IF individualizada e profundamente, de forma pontual no tempo. Juntos, os processos de trabalho cumprem o objetivo da atividade, expressando a competência essencial na prática.

A análise das dimensões da competência foi feita a partir dos processos de trabalho e com base nos parâmetros informacionais. Na dimensão saber, relacionada ao trabalho com o ciclo da informação, algumas tarefas automatizadas permitiram aos supervisores concentrar seu conhecimento na sua tarefa principal: monitorar o risco. Como o ciclo está em grande parte automatizado, o saber relativo às fontes de informação pode ser concentrado em fontes complementares. $\mathrm{O}$ conjunto de conhecimentos que compõe a "tecnologia de supervisão" requer um treinamento específico que inclui aprender a usar as ferramentas de TI. Quanto à utilização dos contextos informacionais, o que influi é o conhecimento prévio sobre sua existência ou suas possibilidades. A experiência na atividade provê conhecimento de um número maior e mais diversificado de fontes e tipos de informação utilizáveis para solucionar problemas. Quanto à TI, sua utilização intensa e a especificidade dos sistemas desenvolvidos requer conhecer as ferramentas e metodologias, indicadores/ critérios utilizados na atividade, e incluídos nos sistemas ou relativos à análise final.

$\mathrm{Na}$ dimensão situacional, relativa ao ciclo da informação, é importante que o supervisor indireto tenha habilidade para utilizar as funcionalidades incluídas nas ferramentas de trabalho, avaliando a efetividade de seu resultado. Essas habilidades só podem ser adquiridas com a experiência no uso das ferramentas, metodologias, indicadores e critérios, de forma que o saber-fazer faça parte da vida diária. O supervisor deve entender a informação como matéria-prima, sabendo lidar com ela no tocante a suportes, formatos, conteúdos, tipos, fontes, tecnologias. Quanto à utilização dos contextos informacionais, o saber fazer está ligado aos mecanismos ativadores e às variáveis intervenientes, que dirigem a utilização para determinados contextos. Os tipos de informação utilizados para resolver problemas atendem a requisitos situacionais referentes a cada processo de trabalho: tipo de análise, tipo e tamanho da IF, tipo de produto de informação a ser oferecido. Quanto à utilização da TI, a habilidade do supervisor é adquirida de acordo com o processo de trabalho no qual está inserido. Cada processo de trabalho compreende ferramentas, metodologias, critérios e indicadores específicos que indicam as NI do processo.

$\mathrm{Na}$ dimensão afetiva, o trabalho com o ciclo da informação está ligado às preferências dos supervisores e ao nível de desenvolvimento do processo de trabalho no qual está inserido. A preferência geral é pela informação em meio eletrônico. Se o processo não está suficientemente desenvolvido e/ou automatizado as preferências se prendem aos meios e à escolha de metodologias, incluindo fontes de informação impressas - não disponíveis no sistema - e pessoas, o que pode reduzir o uso de certos tipos de informação. Quanto mais automatizado o processo mais diversificadas podem ser as opções do supervisor. A experiência de trabalho, a consciência da importância e do alcance desse trabalho, bem como o ambiente de cooperação e a amizade do grupo também influem em suas atitudes. A utilização de contextos informacionais diferentes 
faz parte da prática diária na medida do conhecimento prévio sobre eles e da necessidade de diferentes contextos para solucionar problemas específicos. Cada processo de trabalho demanda o uso de determinadas informações, que podem ser ou não consideradas de acordo com preferências e experiência profissional. Quanto à utilização da TI, espera-se que o supervisor indireto se adapte ao uso intensivo da tecnologia, pois a atividade de supervisão indireta está intrinsecamente ligada a ela.

As competências ligadas especificamente ao processo informacional estão descritas na Tabela 3. A observação dos processos de trabalho permitiu avaliar o uso das competências informacionais na prática de trabalho, já que estas são importantes no que diz respeito ao êxito das tarefas diárias. A consciência do uso da informação como matéria-prima de trabalho e da importância da organização adequada e eficiente desta para a eficiência e eficácia dos processos de trabalho é básica para o perfil do supervisor indireto. A consciência de que uso da TI é imprescindível para a efetividade das tarefas na escala requerida pelo sistema financeiro brasileiro também é um aspecto fundamental desse perfil.

\section{Conclusões}

A análise dos FCS e a observação dos processos de trabalho da atividade de SIIF confirmaram a premissa de que ela era intensiva em informações, ou seja, tem seus processos de trabalho baseados na coleta, processamento, distribuição e uso da informação e nas tecnologias da informação. Isso sublinhou a importância do uso de parâmetros informacionais, como os usados nos modelos de análise das NI e CI para análise e distinção de características dos perfis da atividade e de seus

Tabela 3: As competências informacionais dos supervisores indiretos e suas dimensões.

\begin{tabular}{|l|l|l|l|}
\hline \multicolumn{1}{|c|}{ Comportamentos } & \multicolumn{1}{|c|}{ Conhecimentos } & \multicolumn{1}{c|}{ Habilidades } & \multicolumn{1}{c|}{ Atitudes } \\
\hline $\begin{array}{l}\text { Reconhecem a informação } \\
\text { que utilizam como matéria- } \\
\text { prima para o seu trabalho e } \\
\text { a analisam de acordo com } \\
\text { tecnologia própria. }\end{array}$ & $\begin{array}{l}\text { Conhecem os contextos } \\
\text { informacionais e suas } \\
\text { peculiaridades, e as possibili- } \\
\text { dades de aplicação das TI } \\
\text { disponíveis. }\end{array}$ & $\begin{array}{l}\text { Desenvolvem a capacidade } \\
\text { de análise da massa } \\
\text { documental existente e } \\
\text { de identificar novas NI. }\end{array}$ & $\begin{array}{l}\text { Possuem disponibilidade } \\
\text { para trabalhar com a infor- } \\
\text { mação no modelo extensivo } \\
\text { de comunicação. }\end{array}$ \\
\hline $\begin{array}{l}\text { Organizam a informação } \\
\text { de acordo com os objetivos } \\
\text { da tarefa que realizam e } \\
\text { elaboram produtos de } \\
\text { informação. }\end{array}$ & $\begin{array}{l}\text { Conhecem a tecnologia de } \\
\text { supervisão indireta e sua } \\
\text { ligação com a tecnologia de } \\
\text { informação. }\end{array}$ & $\begin{array}{l}\text { Desenvolvem a habilidade } \\
\text { de transformar a tecno- } \\
\text { logia da supervisão } \\
\text { indireta com a ajuda } \\
\text { da TI. }\end{array}$ & $\begin{array}{l}\text { Possuem disposição para } \\
\text { aprender e diversificar } \\
\text { conhecimentos e fazer } \\
\text { mediação entre a massa } \\
\text { documental e suas possibi- } \\
\text { lidades de uso. }\end{array}$ \\
\hline $\begin{array}{l}\text { Utilizam informações de } \\
\text { diversos contextos para } \\
\text { complementar a análise } \\
\text { preliminar realizada pela } \\
\text { ferramenta de trabalho. }\end{array}$ & $\begin{array}{l}\text { Conhecem os sistemas de } \\
\text { informação disponíveis e } \\
\text { suas possibilidades. }\end{array}$ & $\begin{array}{l}\text { Desenvolvem habilidade } \\
\text { de reconhecer novas NI } \\
\text { em novos contextos. }\end{array}$ & $\begin{array}{l}\text { Possuem disposição para } \\
\text { troca de informações e } \\
\text { conhecimentos. }\end{array}$ \\
\hline $\begin{array}{l}\text { Utilizam a TI para ganhar } \\
\text { efetividade e eficácia no } \\
\text { seu trabalho diário. }\end{array}$ & $\begin{array}{l}\text { Conhecem as possibilidades } \\
\text { de uso da TI com relação à } \\
\text { tecnologia de supervisão. }\end{array}$ & $\begin{array}{l}\text { Desenvolvem habilidade } \\
\text { de negociar espaços de } \\
\text { uso da TI. }\end{array}$ & $\begin{array}{l}\text { Sào inquisitivos e abertos } \\
\text { às possibilidades de modifi- } \\
\text { cação e melhoria do nível } \\
\text { tecnológico existente. }\end{array}$ \\
\hline
\end{tabular}

Fonte: Miranda, 2007. 
profissionais. Uma ligação possível de ser estabelecida entre os temas reunidos pelos FCS da atividade de SIIF, as dimensões das NI dos profissionais de supervisão indireta e suas competências está expressa na Figura 4. entre uma grande massa de dados e informações e o seu uso.

O tema Informação é marcado por aspectos cognitivos que dependem da informação disponível e da capacidade de lidar com a massa de documentos

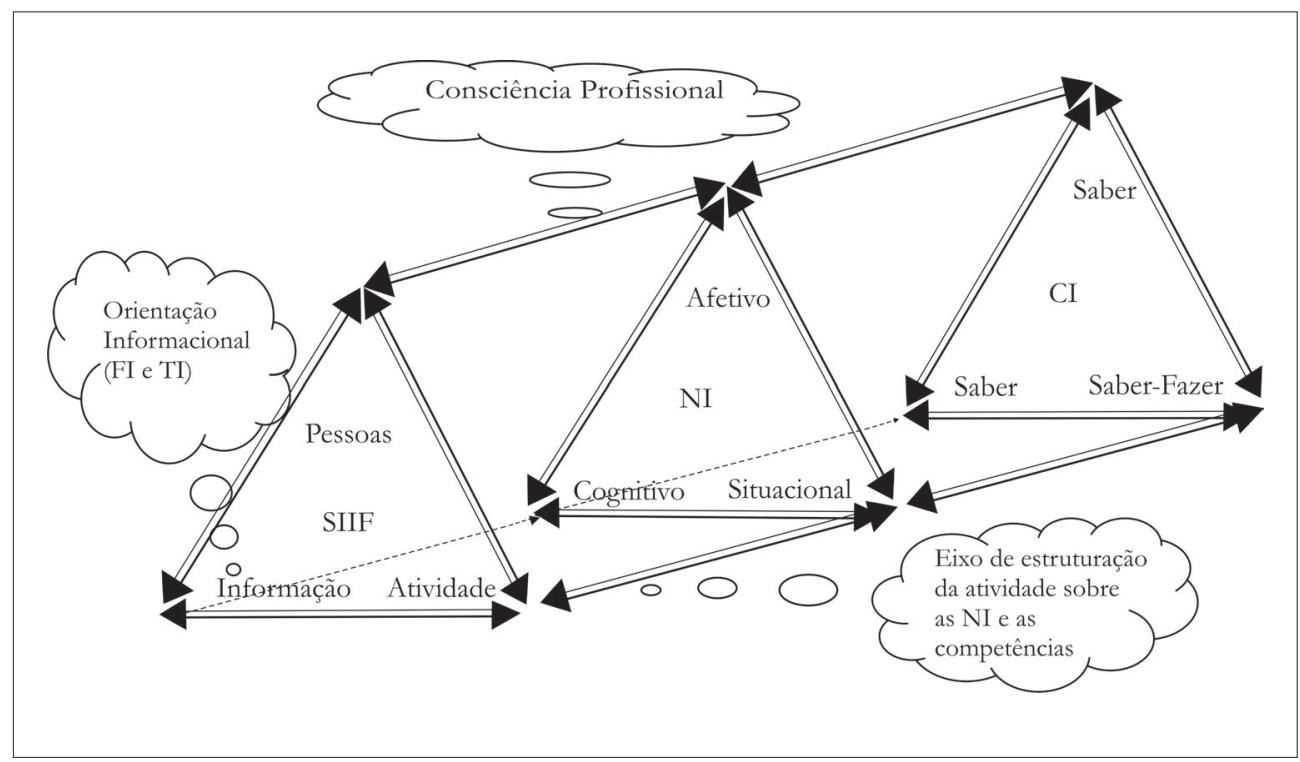

Fonte: Miranda, 2007

Fig. 4: As NI, as competências e os FCS da atividade de SIIF.

O "eixo" situacional é o que tem poder estruturador, dadas as características da prática profissional que guiam a percepção das NIs dos supervisores e o desenvolvimento de seu saber fazer. O "eixo" cognitivo poderia ser considerado o eixo de orientação informacional, que contempla esforços de gestão de informação e da tecnologia de informação, dirigindo a construção do saber. O "eixo" afetivo poderia ter como foco a consciência profissional, que no caso do supervisor indireto poderia ter como referência o profissional de informação, considerandose algumas das características similares como, por exemplo, o fator mediador existente. $\mathrm{O}$ aspecto cognitivo ou o saber necessário às tarefas relaciona-se ao conhecimento dos aspectos informacionais da atividade, sugerindo o desenvolvimento de competências relacionadas ao uso da informação e das TIs. Os fatores situacionais da atividade estão ligados ao seu nível de desenvolvimento tecnológico. Este, por sua vez, está ligado às habilidades desenvolvidas pelos supervisores indiretos no trato com a informação e com as tecnologias que utilizavam. O tema Pessoas relaciona a dimensão afetiva ao saber agir de forma a definir uma "cultura informacional" que deveria integrar o perfil do profissional de supervisão 
indireta. $\mathrm{O}$ desenvolvimento da competência informacional, associado à convivência com os grupos de pessoas com tarefas comuns, poderia depender da formação e proveniência de cada profissional ao se engajar na atividade.

Conforme Le Boterf (2006), o estudo de competências não deve limitar-se a seu mapeamento e sim oferecer algum referencial para o seu desenvolvimento.
A Figura 5 traz alguns referenciais formulados tanto para a percepção das necessidades dos supervisores quanto para o desenvolvimento de suas competências, especialmente as competências informacionais.

Os mecanismos de ativação estão dispostos em oportunidades de aprendizagem, inovação, diversificação e criação de novas capacidades de avaliação.

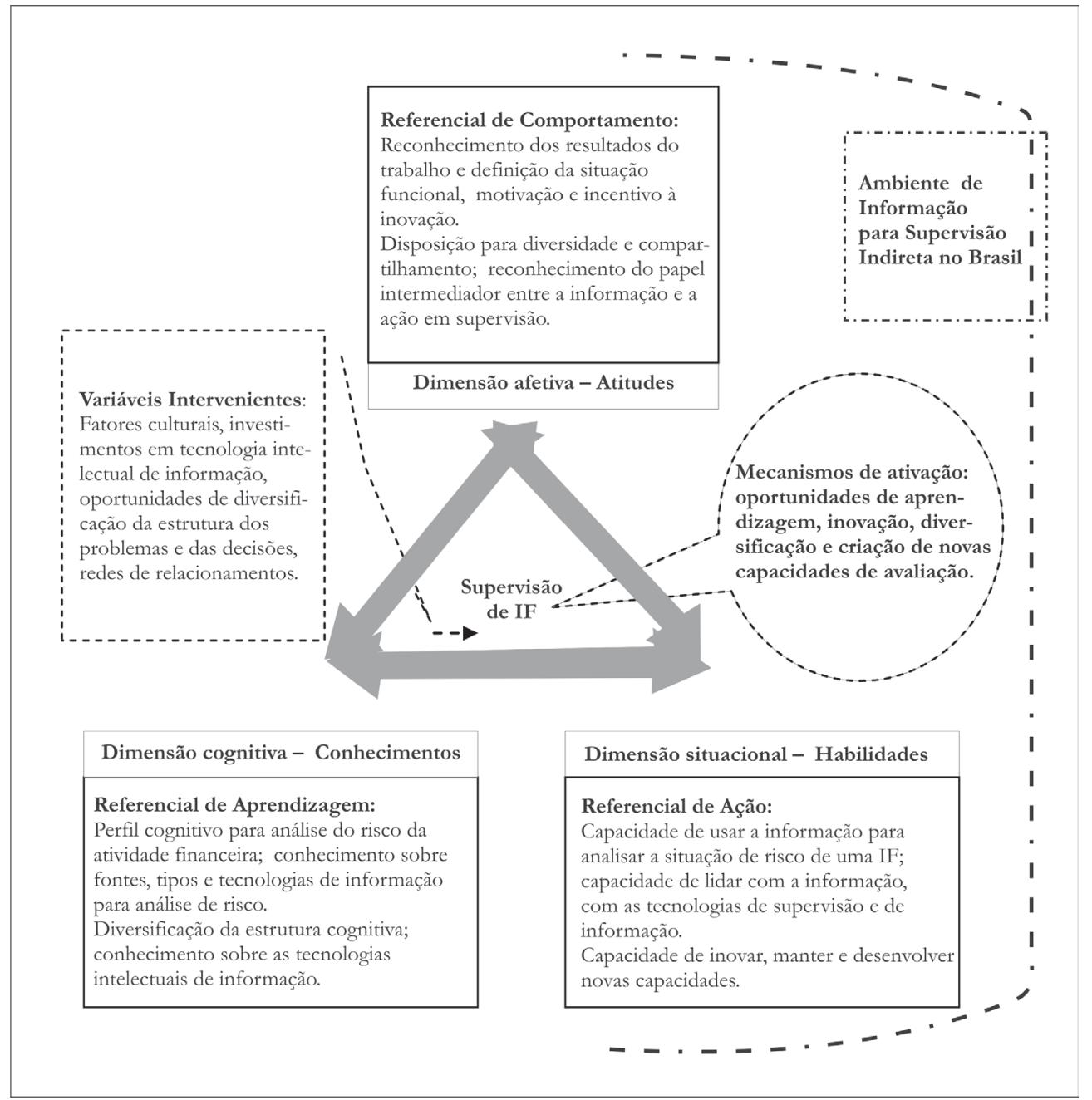

Fonte: Miranda, 2007

Figura 5: Referenciais de NI e CI para a Supervisão Indireta de IF no Brasil. 
Conclui-se que as NI dos supervisores indiretos e as suas CI estão estreitamente ligadas às necessidades específicas de seus processos de trabalho: fatores situacionais - tarefas, rotinas e tecnologias. O "papeltrabalho", como propôs Wilson (1981), define um conjunto de necessidades que, por sua característica, só poderia ser atendido por meio de um perfil profissional específico, desenvolvido na própria atividade. Nesse perfil, a competência em lidar com a informação faz-se um item fundamental.

(Artigo recebido em 6 de agosto de 2007. Versão final em 30 de abril de 2008).

\section{Notas}

*A pesquisa foi financiada pelo Banco Central do Brasil e orientada pela Prof ${ }^{a} \operatorname{Dr}^{a}$ Kira Tarapanoff. As opiniões expressas no texto são de inteira responsabilidade da autora, não significando posição oficial da instituição financiadora da pesquisa.

1 O Ciclo da Informação identifica todas as fases do trabalho com a informação: coleta, armazenamento, distribuição, recuperação e uso. A Tecnologia da Informação pode ser definida como tecnologia que influi na arquitetura do conhecimento registrado (suporte, formato, conteúdo e tipo), e que, na "era da informação", envolve computadores, telecomunicação e sistemas de softwware que ajudam a organização, transmissão, armazenamento e utilização de grandes volumes de dados, informações e conhecimentos a baixo custo e alta velocidade, viabilizando diversas aplicações. Os Contextos Informacionais são os contextos onde se realiza o ciclo informacional que, influenciando no fluxo da informação e em suas características, diferenciam os tipos de informação: informação tecnológica, para negócios, científica etc.

2 Profissionais de informação fazem mediação entre criadores, provedores, usuários e as tecnologias da informação. Dentre os profissionais de informação, os que têm estado à frente do movimento Information Literacy são os bibliotecários.

3 O método FCS procura identificar as características, condições ou variáveis que deverão ser devidamente monitoradas e gerenciadas, podendo ser usado como ferramenta para definir as necessidades de informação e as características essenciais de uma atividade ou organização. A técnica usada foi proposta por (Rockart, 1979): entrevistas conduzidas em duas ou três sessões separadas. Na primeira, os objetivos dos executivos são relatados e os FCS que os sustentam são discutidos. Uma segunda sessão é usada para rever as informações, após um tempo de amadurecimento. Pode ser necessária uma terceira sessão para obter o resultado final.

4 O processo de comunicação extensiva é semelhante ao da leitura extensiva (de um hipertexto, por exemplo), que se efetiva sem regras predefinidas, sem um padrão fixo, sem fronteiras técnicas ou controle que o limite. O importante é uma finalidade a ser cumprida, um objetivo a ser alcançado e instituído (Simeão, 2003). 


\section{Referências bibliográficas}

Albagli, Sarita. Informação, Conhecimento e Desenvolvimento. Florianópolis: Encontro Nacional de Pesquisa em Ciência da Informação (ENANCIB), 6º 2005.

Almeida, Carlos C. Discurso do Sujeito Coletivo: reconstruindo a fala do "social". In: Valentim, M. L. P. (org.) Métodos Qualitativos de Pesquisa em Ciência da Informação. São Paulo: Polis, 2005, p. 119-134.

Choo, Chun Wei. The Knowing Organization. New York: Oxford University Press, Inc., 2006.

- A Organização do conbecimento: como as organizações usam a informação para criar significados, construir conhecimento e tomar decisões. Trad. Eliana Rocha, São Paulo: Editora Senac São Paulo, 2003.

Closing the Cognitive Gaps: how people process information. Financial

Times: London, Mar 22, 1999.

. Human Information Seeking Behaviors. Helsinki: Politics \& Internet

Conference, $2^{\text {nd }}$ International Congress on Electronic Media \& Citizenship in Information Society, Keynote Presentation, Jan 1999a.

Dudziak, Elisabeth A. A Information Literacy e o papel educacional das bibliotecas. São Paulo: Universidade de São Paulo-ECA-USP, Dissertação de Mestrado, 2001.

Fleury, A. e Fleury, M.T. L. Estratégias Empresariais e Formação de Competências: um quebracabeça caleidoscópico da indústria brasileira. $2^{a}$ ed., São Paulo: Atlas, 2001.

Franco, Maria Laura P.B. Análise de Conteúdo. 2ª ed. Brasília: Liver Livro Editora, 2005.

González Rey, Fernando L. Pesquisa Qualitativa e Subjetividade. Trad.: Marcel A.F. Silva, São Paulo: Pioneira Thomson Learning, 2005.

Grant, Robert M. The Resource-Based Theory of Competitive Advantage: implications for strategy formulation. California Management Review, v. 33, no 3, p. 114-135, Spring 1991. Guimarães, T. de A. A Nova Administração Pública a Abordagem da Competência. Rio de Janeiro: RAP - Revista de Administração Pública, v. 34, nº 3, p. 124-40, mai-jun 2000.

Le Boterf, Guy. Desenvolvendo a Competência dos Profissionais. Trad.: Patrícia Chittoni R. Reuillard, $3^{\text {a }}$ ed. revista e ampliada. Porto Alegre: Artmed, 2003.

Le CoAdic, Yves F. Le Besoin D'Information. Paris: ADBS Editions, 1998.

Marcial, Noel A. Normas de competência em información. BiD: textos universitaris de Biblioteconomia i Documentació, no 11, dec 2003. Disponível em: <http://www2.ub.es/ bid/ consulta_articulos.php?url=http:// www.ub.es/bid/11 angul1.htm\#1\&issn=15755886\&numero $=11>$. Acesso em: 11.04.2005.

Miranda, Silvânia V. Identificação de Necessidades de Informação e sua relação com Competências Informacionais: o caso da Supervisão Indireta de Instituições Financeiras no Brasil. Brasília: Tese de Doutorado, Universidade de Brasília, 2007.

Miranda, Silvânia V. Identificando Competências Informacionais. Brasília: Ciência da Informação, v. 33, n 2, mai-ago 2004, p. 112-122.

Prahalad, J.K. e Hamel, G. The Core Competence of the Corporation. Harvard Business Review, p. 79-91, may-jun 1990. 
ROCKART, John F. Chief Executives define their own data needs. Harvard Business Review, v. 57, no 2, p. 81-93, mar-apr 1979.

Simeño, Elmira L. M. S. Comunicação Extensiva e o Formato do Periódico Científico em Rede. Brasília: Tese de Doutorado, Universidade de Brasília, 2003.

Valentim, Marta L.P. Análise de Conteúdo. IN: Valentim, M.L.P. (org.) Métodos Qualitativos de Pesquisa em Ciência da Informação. São Paulo: Polis, 2005, p. 119-134.

VIRKUS, Sirje. Information literacy in Europe: a literature review. Information Research, v. 8, $\mathrm{n}^{\circ}$ 4, jul 2003. Disponível em: < http:/ /informationr.net/ir/8-4/paper159.html>. Acesso em: 21.03.2005.

WiLSON, T.D. Alfred Schutz, phenomenology and research methodology for information behaviour research. In: ISIC4 - Fourth International Conference on Information Seeking in Context, Universidade Lusiada, Lisbon, Portugal, Sep 11 to 13, 2002. Disponível em: <http://informationr.net/tdw/ publ/papers/schutz02.html>, Acesso em: 28.12.2003.

. Human Information Behavior. Informing Science, v. 3, no 2, p. 49-55, 2000.

Disponível em: <http://inform.nu/Articles/Vol3/v3n2p49-56.pdf>, Acesso em: 20.12.2004.

. Recent trends in user studies research and qualitative methods. Information Research, v. 5, no 3, march 2000a, Disponível em: <http://www.informationR.net/ir/5-3/ paper 76.html>. Acesso em: 05.05.2003.

. On user studies and information needs. Journal of Librarianship, v. 37, $\mathrm{n}^{\circ} 1$, p. 3-15, 1981. Disponível em: <http://informationr.net/tdw/publ/papers/ 1981 infoneeds.html>. Acesso em: 28.12.2003.

Zarifian, Philippe. Le modèle de la compétence. $2^{\mathrm{e}}$ édition actualisée. Paris: Éditions Liaisons, 2004.

. Objetivo Competência: por uma nova lógica. Trad. Maria Helena C.V'Trylinski, São Paulo, Atlas, 2001.

. O Modelo da Competência: trajetória histórica, desafios atuais e propostas.

Trad. Eric R. R. Heneault, São Paulo: Editora Senac São Paulo, 2003. 


\section{Resumo-Resumen-Abstract}

\section{Necessidades de informação e competências informacionais no setor público: um estudo de caso}

Silvânia Vieira de Miranda

O texto apresenta parte do referencial teórico de pesquisa de doutorado, que buscou estabelecer relações teóricas e práticas entre as necessidades de informação de uma determinada atividade e as competências informacionais desenvolvidas para atendê-las. A premissa da pesquisa foi que a atividade estudada, a supervisão indireta de instituições financeiras, era intensiva em informação e poderia ser estudada como atividade informacional, a partir do uso de parâmetros informacionais. Os parâmetros utilizados nos modelos teóricos foram o ciclo e a tecnologia da informação e os contextos de comunicação da informação. A pesquisa empírica se iniciou com a identificação dos fatores críticos de sucesso da atividade, visando a posterior mapeamento das necessidades de informação e das competências dos profissionais supervisores. Os resultados obtidos e sua análise permitiram relacionar os fatores críticos de sucesso da atividade às necessidades de informação dos profissionais de supervisão indireta e às suas competências informacionais.

Palavras-chave: necessidades de informação, competências informacionais, fatores críticos de sucesso.

\section{Necesidades de información y competencias informacionales en el sector público: un estudio de caso \\ Silvânia Vieira de Miranda}

Este texto presenta parte de la base teórica de una investigación de doctorado, tratando de los temas: las necesidades de información y las capacidades. La investigación fue basada en la premisa que la actividad estudiada - supervisión indirecta de instituciones financieras - era intensiva en información y se podría estudiarla por medio de parámetros del trabajo con la información. Los parámetros elegidos para analizar necesidades de información y el desarrollo de capacidades eran: ciclo de la información; tecnología de información; y contextos de la comunicación de la información. La investigación comenzó con la identificación de los factores críticos del éxito de la actividad, intentando identificar las necesidades de información y las competencias del grupo profesional de la supervisión indirecta. Los resultados obtenidos y su análisis proporcionaron un acoplamiento entre los factores críticos del éxito de la actividad, las necesidades de información de los profesionales estudiados, y sus capacidades en información.

Palabras Claves: necesidades de información, capacidades en información, factores críticos del éxito.

\section{The need for information and informational competencies in the public sector: a case study} Silvânia Vieira de Miranda

This text presents part of theoretical basis of a doctorate research, concerning to the subjects information needs and competencies. The research was based on the premise that the activity studied - Off-site supervision of financial institutions - was information intensive and could be studied by means of information work parameters. The chosen parameters to analyze information needs and the development of competencies were: information cycle; information technology, and contexts of information communication. The research started with the identification of critical success factors of the activity, seeking to map information needs and competencies of the Off-site supervision professional group. The results obtained and its analysis provided a link between critical success factors of the activity, information needs of the professionals studied, and their information competencies.

Keywords: information needs, information competencies, critical success factors. 
Silvânia Vieira de Miranda

Economista, mestre em Ciência Política, especialista em Inteligência Organizacional e Competitiva, doutora em Ciência da Informação, analista do Banco Central do Brasil.

Contato da autora: silvania.miranda@bcb.gov.br 